\title{
Multisectoral Integrated Structures Key Competences. Regional Aspect
}

\author{
Khairullin Algis
}

Kazan Federal University, Institute of Management, Economics and Finance, Kazan, 420103, Russia

Email: han-kazan@mail.ru

Doi:10.5901/mjss.2014.v5n24p307

\begin{abstract}
The article considers the nature and content of multisectoral integrated structures. There are given examples of region multisectoral integrated structures and designated their contribution to the regional economies development and to the multisectoral industry clusters formation. There is a classification of the key competences by the most significant economic and administrative features: the implementation scope, relation to the process of intraorganizational integration, competencies scalability, character of competencies formation, features of the impact on the regional economy. Comparative effectiveness of multisectoral integrated structures index is grounded. Testing of the proposed index carried out on the materials of one of the largest Tatarstan Republics multisectoral integrated structures - JSC "Ak Bars Holding Company". Based on the results of testing are revealed points of reducing the effectiveness of the considered company, are made suggestions for their improving.
\end{abstract}

Keywords: multisectoral organizations, integration, effectiveness, key competences, the region's economy.

\section{Introduction}

Multisectoral integrated structures play an important role in the development of modern regional socio-economic systems. According to D. Crump multisectoral integrated structures can operate in three main forms: large diversified corporations, holding structures and vertically integrated companies, which uniting enterprises entering into a one productiontechnological chain [4]. In our view, to the enterprises of this kind should also include multi-directional government corporations and financial-industrial groups.

Multisectoral integrated structures ensure the implementation of large-scale cross-sectoral investment projects, thereby contributing to increase in employment in the region's economy and ensure the enhanced fullness of regional budget in part of income tax and the tax on personal income. Inside the integrated cross-sectoral formations are formed additional organizational and financial capacities for the implementation of innovative initiatives and the formation of infrastructure projects and programs.

It should be noted that in the regional economy of the Republic of Tatarstan functioning various multisectoral integrated structures. Thus, in particular, JSC "Ak Bars Holding Company" is a diversified multisectoral corporation in which are presented several vertical production process chains (production and processing of agricultural products - food industry - trade sector, the forest industry - woodworking - building materials industry - building complex). Strong corporate integration with the largest regional financial and credit institute - JSC "Ak Bars Bank" - gives financial and economic stability to the diversified company.

Another example: JSC "Tatgazinvest" provides services by the gasification and maintenance for the "Gazprom's" gas mains and other similar objects. This diversified integrated company includes a number of small and medium-sized enterprises producing equipment for gas pipelines, components, auxiliary materials and rendering services, thereby forming a regional distribution cluster of the Republic of Tatarstan.

Finally, there is the largest diversified integrated corporation in the regional economy of the Republic of Tatarstan JSC "Tatneftekhiminvestholding", linked on the conditions of industrial cooperation enterprises which forming a vertically integrated production-processing chain in the field of oil refining, petrochemical and chemical industries. This corporation is not only one of the largest taxpayers in the budget of the region, but also ensures the implementation of a number of social programs and projects, particularly in the area of formation and development of industrial and social welfare infrastructure.

\section{Theory}

According to many researchers, multisectoral integrated structures play a fundamental role in the economy. J. Pescatore 
pointed to their particular importance in the development of scientific and technical progress, generating and implementing innovations as early as 1974 [6]. Later R. Abrams [1] and P. Drucker [5] argued the role of multisectoral integrated structures in enhancing innovation processes, the formation and development of industrial clusters.

L. Brown notes the crucial role of diversified production structures to generate synergies in various areas, such as the acceleration of the process of creating new assortment positions of products, the formation of large-scale training programs for staff, implementation of infrastructure projects [3]. However, we have to agree with the Michael Porter's opinion that creation of long-term positive synergies in diversified corporations is possible only if each of their divisions has enough detailed, science-based development strategy, based on the synthesis of which is formed a common strategy of socio-economic development of the multisectoral integrated structure [7].

The positive effect of large diversified companies in the development of regional socio-economic systems, improving their competitiveness in general recognized by a number of researchers [8], [9]. D. Ulesov, G. Murtazina and L. Safiullin allocate special role of large multisectoral structures in the formation of the modern knowledge economy [10]. In this regard, it should be noted that the multisectoral industrial formations are traditionally more significant organizational and financial opportunities for the creation and development of corporate training centers, including corporate universities, than in other types of companies. This kind of centers not only provide long-term sustainable improvement in productivity this very diversified structure, but also contribute to the improvement of the educational potential of the region's economy as a whole.

It should be noted, that in the Republic of Tatarstan not one of the multi-structures, including such significant financially and organizationally as JSC "Tatneftekhiminvestholding" or "Ak Bars Holding Company", are not created yet corporate universities. In our opinion, it is connected with a certain inertia of diversified structures management thinking, lack of understanding of the role of the system corporate entity in their development. In addition, the multisectoral integrated structures play a significant role in stimulating the progressive development of small, including innovation, entrepreneurship in the region's economy [2].

Thus, the main functions of the multisectoral integrated companies are:

- providing a positive synergistic effect due to the formation and use of sustainable cooperation and integration relations between enterprises of different industries;

- realization of large-scale cross-industry investment projects, which would not be available for implementation at the level of a specialized company because of financial and organizational-economic limits;

- the formation of additional features to activation the processes of financing of research and development activities, including cross-cutting;

- active participation in the formation and improvement of regional production and social-welfare infrastructure, the implementation of large-scale programs of corporate social responsibility;

- assistance in accelerated formation of a knowledge economy, the development and improvement of intellectual capital through additional financial and institutional capacities, including in terms of ensuring the active processes of educational-industrial cooperation with institutions of higher and middle specialized education in the region;

- growth of opportunities for lobbying activities, including legal character activities, provided by the regional Chamber of Commerce, business associations, etc.

However, in the special literature is not revealed enough the issue about the specifics of multicore integrated entities competencies, the classification of this kind of competencies, features of estimation of economic efficiency of functioning and development of multisectoral structures.

\section{Results}

Key competences of diversified integrated structures are their most important functions, accumulated knowledge, develop skills activities to ensure the generation and implementation of competitive advantages. It is obvious that the system of multisectoral integrated structures competencies should have some differences from the competencies of large specialized corporations. In particular, for the multisectoral nature integrated companies are particularly important competences related to the organization and implementation interaction between separate units, with circulation of information between structures of diversified company, with ensuring effective integration processes in the field of generation and introduction of innovations, with formation and implementation of joint large-scale investment projects, social programs that are relevant to corporation as a whole, etc.

Formation of diversified integrated company's core competences system requires specialized knowledge and skills in the sphere of multisectoral production technology plan and characteristics of management systems for the 
administrative personnel of the corporate structure of the species.

The author proposes classification of multisectoral integrated formations key competences by the most significant economic and managerial characteristics (Table 1).

The first of the highlighted in Table 1 multisectoral integrated structures key competences classification features is common to both types of structures under consideration, and for the companies of a different type; subsequent classification features are specific to organizations is primarily the multisectoral nature of the activities.

Table 1. Classification of multisectoral integrated structures key competences (Based on own researches)

\begin{tabular}{|c|c|}
\hline Classification features & Types of key competences \\
\hline 1 Scope of implementation & $\begin{array}{l}\text { - production competences; } \\
\text { - financial competences; } \\
\text { - scientific and innovative competences; } \\
\text { - competences in the sphere of personnel management; } \\
\text { - marketing competences, etc. }\end{array}$ \\
\hline $\begin{array}{l}2 \text { Relationship to intraorganizational } \\
\text { integration process }\end{array}$ & $\begin{array}{l}\text { - Specific competences of individual activities (sectors) of the structure; } \\
\text { - Specific competences of integration processes between activities; } \\
\text { - Specific competences to manage a diversified structure as a whole. }\end{array}$ \\
\hline 3 Competencies scalability & $\begin{array}{l}\text { - non-scalable competences; } \\
\text { - competences scalable within a multidisciplinary structure with minor } \\
\text { modifications; } \\
\text { - competences scalable with significant modifications; } \\
\text { - competences scalable without modification (standard). }\end{array}$ \\
\hline 4 Character of competencies formation & $\begin{array}{l}\text { - competences developed by outside organizations (for example, by } \\
\text { consultants); } \\
\text { - competences created by experts of this very diversified structure. }\end{array}$ \\
\hline $\begin{array}{l}5 \text { Features of the impact on the regional } \\
\text { economy }\end{array}$ & $\begin{array}{l}\text { - competences, forming secondary effects in the region real economy sectors; } \\
\text { - competences, creating secondary effects in the service sector of the regional } \\
\text { economy and infrastructure sector; } \\
\text { - competences, without significantly affecting on the development of the region } \\
\text { economy. }\end{array}$ \\
\hline
\end{tabular}

So, depending on the relationship to the integration process is proposed to differentiate the key competences to the characteristic for certain types of diversified organization economic activities and to related to processes of integration between different types of activities. The latter include some innovative ways of interaction between the activities within a multisectoral structure, methods of formation and realization of cross-sectoral industrial projects, interbranch R \& $D$, organization of intra-settlement etc. In addition, it is advisable to identify the key competences that are typical for multisectoral organization management system as a whole, the content of which significantly differ from the specialized company management competences.

Diversified organization key competencies classification, depending on their degree of scalability, i.e. the ability to use in a wide range of departments and activities of the organization, has fundamental importance. So, those manufacturing, financial, human and other competences that are formed within one of the activities of a multisectoral organization and cannot be used in other activities are non-scalable. Ideally, most of the key competences of a multisectoral organization must be scalable, albeit with some modifications, within all or the vast majority of directions of activity across industries.

From formation character positions key competences that are created by specialists of this very diversified organization are particularly important. In our opinion, under the same conditions, this kind competencies in most cases are higher quality than competences generated by third-party consultants. It should be noted that using the third-party services for the formation of the key competences is increase the risk of leakage of confidential information that economically significant for the diversified production formation.

Finally, diversified integrated organization key competencies classification is importance for the regional economy. Ideally, this kind competencies should provide multidirectional secondary positive effect for all sorts of regional economy organizations (small enterprises involved by the subcontract, the scope of specialized logistics and service companies, higher education institutions under the conditions of industrial-educational cooperation, etc.).

Separate methodological problem is the evaluation of functioning and development of integrated multisectoral organization effectiveness, instruments of which obviously must be different from the effectiveness evaluating 
instrumentation of a specialized company. This kind of evaluation is necessary, first of all, to identify the most significant reserves for increasing the effectiveness of multisectoral organization and consequently improving the system of key competences aimed at effective mobilization of these reserves.

To solve the problem of complex effectiveness evaluation of diversified companies we propose index of the comparative effectiveness of multisectoral integrated organization (1):

$I=(T \div \sigma) \times(R m \div R r) \times K e$

where I - proposed index of the comparative development effectiveness of the multisectoral integrated organization;

$\mathrm{T}$ - average weighted rate of physical volume growth of organization activities (a proportion of the organization activities in revenue structure by industry acts as the weights);

$\sigma$ - standard deviation of rates of growth of the physical volume of the multisectoral integrated organization activities;

$\mathrm{Rm}$ - average profitability of multisectoral integrated organization;

$\mathrm{Rr}$ - average profitability of similar activities on the regional economy as a whole;

$\mathrm{Ke}$ - elasticity coefficient of profitability changes according to growth rates dynamics of the average index of physical volume of multisectoral integrated organization production.

Thus, the proposed formula for the index of the comparative effectiveness of multisectoral integrated organization considers the intensity of its functioning (the growth rate of physical volume) and the balance of rates of activities development by industry (ideally standard deviation of growth rates should be minimal), and also one of the most common indicators of financial and of economic productivity of the organization - profitability, which correlating with the similar activities profitability on the region's economy as a whole.

Finally, the effectiveness index will be higher, the higher coefficient of elasticity of profitability changes in depending on the dynamics of the average index of physical volume. Ideally, this type elasticity coefficient must exceed one, that will indicate the presence of multiplier effect - the accelerated profitability growth as a result of the positive physical volume of production changing.

Carried out approbation of the proposed index of comparative effectiveness of multisectoral integrated organization on the materials of "Ak Bars Holding Company" (Republic of Tatarstan) - regionally important multisectoral holding. Initial data for calculation of the proposed index in the context of consolidated types of economic activity of the multisectoral organization are presented in Table 2. It should be noted that, despite the post-crisis recovery of the company in 2010 2013 and a small stable exceeding the average profitability of over the same period of the RT regional economy as a whole, in 2007 - 2013 index of relative effectiveness of multisectoral organization has a tendency to reduce.

Overall, industrial production acts as basic aggregated economic activity by industry for JSC "Ak Bars Holding Company". In 2006 - 2013, except 2009 (the peak of the global financial and economic crisis), investigated multisectoral integrated company characterized by positive growth of real physical volume of industrial production, that indicating high competitiveness level of holding enterprises products. In the agricultural production sphere holding structures show less satisfactory rates of development what is connected with certain difficulties of financing this activity sphere and with a relatively high level of basic production assets depreciation in agriculture. Rates of development instability in trade and services enterprises belonging to the this multisectoral integrated company connected with a high level of competition in the relevant industry markets in the Republic of Tatarstan regional economy, especially in the post-crisis period of 2010 2013.

Table 2. Initial data and evaluation of the proposed index of the comparative development effectiveness of JSC "Ak Bars Holding Company" multisectoral organization

\begin{tabular}{|c|c|c|c|c|c|c|c|c|}
\hline Indicators & 2006 & 2007 & 2008 & 2009 & 2010 & 2011 & 2012 & 2013 \\
\hline \multicolumn{9}{|c|}{ Real growth rates of the physical output volume, times to previous year } \\
\hline 1.Industry & 1,05 & 1,08 & 1,01 & 0,97 & 1,04 & 1,06 & 1,05 & 1,07 \\
\hline 2.Agroindustrial complex & 1,06 & 1,07 & 0,97 & 0,94 & 0,95 & 1,01 & 0,99 & 1,01 \\
\hline 3. Service sphere & 1,09 & 1,11 & 1,04 & 1,02 & 1,11 & 1,12 & 1,07 & 0,89 \\
\hline 4 Trade & 1,11 & 1,12 & 1,04 & 0,99 & 1,03 & 1,12 & 1,01 & 1,15 \\
\hline 5 Others & 1,06 & 1,07 & 1,11 & 1,01 & 0,94 & 0,93 & 1,02 & 0,98 \\
\hline \multicolumn{9}{|c|}{ The share of the revenue structure, $\%$} \\
\hline 1.Industry & 71,10 & 72,30 & 70,90 & 69,80 & 71,10 & 72,90 & 73,40 & 73,70 \\
\hline 2.Agroindustrial complex & 10,50 & 10,90 & 9,90 & 9,20 & 9,00 & 9,40 & 9,00 & 9,20 \\
\hline
\end{tabular}




\begin{tabular}{|l|c|c|c|c|c|c|c|c|}
\hline 3. Service sphere & 3,20 & 3,10 & 2,90 & 2,80 & 2,60 & 2,70 & 2,60 & 2,60 \\
\hline 4 Trade & 9,60 & 10,40 & 10,80 & 10,60 & 10,90 & 11,20 & 11,30 & 12,50 \\
\hline 5 Others & 5,60 & 3,30 & 5,50 & 7,60 & 6,40 & 3,80 & 3,70 & 2,00 \\
\hline Average weighted rate, times (T) & 1,06 & 1,08 & 1,02 & 0,97 & 1,03 & 1,06 & 1,04 & 1,07 \\
\hline Standard deviation of rates of growth ( $)$ & 0,02 & 0,01 & 0,03 & 0,02 & 0,04 & 0,04 & 0,02 & 0,05 \\
\hline $\begin{array}{l}\text { The profitability of multisectoral integrated organization 's attitude to } \\
\text { the average profitability by the Republic of Tatarstan, times (Rm / Rr) }\end{array}$ & 1,02 & 1,05 & 1,07 & 1,04 & 1,03 & 1,10 & 1,04 & 1,03 \\
\hline $\begin{array}{l}\text { Elasticity coefficient of profitability changes according to growth rates } \\
\text { dynamics of the average index of physical volume (Ke) }\end{array}$ & $\mathrm{x}$ & 1,01 & 1,09 & 1,11 & 1,04 & 1,08 & 1,04 & 1,00 \\
\hline $\begin{array}{l}\text { Index of the comparative development effectiveness of the } \\
\text { multisectoral integrated organization (I) }\end{array}$ & $\mathrm{x}$ & 81,94 & 42,02 & 64,56 & 30,33 & 33,86 & 53,64 & 23,85 \\
\hline
\end{tabular}

Sustained excess average level of profitability in the holding of the average profitability in the Republic of Tatarstan regional economy as a whole indicates the effectiveness of investigated multisectoral integrated company.

The main reasons for the decline of the comparative effectiveness of multisectoral integrated structures index of the JSC "Ak Bars Holding Company" in 2007 - 2013, as shown in Table 2, are:

- the standard deviation of the activities growth rates substantial increase in 2006 - 2013 indicates the lack of balance in the organization development by industry and the inadequacy of using the potential of production integration between enterprises belonging to the holding company;

- not high enough (though somewhat greater than unity) coefficient of elasticity of profitability depending on changes in the physical volume of production, that indicating substantial absence of a multiplier effect on income and profitability of the investigated organization.

Accordingly, to improve the efficiency investigated multisectoral organization should develop competencies related to the integration of activities within the organization, to develop the production-process chains (industry - trade, agriculture - light industry - trade), to orient holding service industries companies for complex maintenance, in the first place, needs of different economic activities enterprises. This will allow to reduce the level of the growth rates standard deviation and, consequently, to increase the level of effectiveness of multisectoral organization in the medium term.

At the same time, ideally, integration between departments multisectoral integrated company must be diverse, include both strong industrial and technological relations and joint investment and infrastructure projects, innovative initiatives, general educational and social programs. This kind of diverse integration, as a rule, is the most strategically stable.

To increase the elasticity of profitability depending on changes in the rates of change of production volume appropriate to develop and adopt new complex intraorganizational program of consistent cost reduction: through the development of budgeting, thrifty manufacturing, optimization of flow processes within the holding company, the introduction of a unified ERP-system of control over industrial, financial and commercial processes.

\section{Conclusions}

In general, developed classification of multisectoral integrated organizations key competences by the most significant economic and management features allows more exactly differentiate multisectoral corporation's competences and to identify their specific depending on trends in enterprise integration.

The proposed index of comparative efficiency of multisectoral integrated organization allows comprehensively assess the multisectoral company development effectiveness in the dynamics, as well as to compare similar by industry activities structures diversified organizations with each other. In addition, on the basis of this index it is possible to identify the most significant reserves to enhance the functioning and development of multisectoral organization (problem areas that impede improve the efficiency) and to develop measures for improving organization's key competences aimed at effective mobilization mentioned reserves to improve efficiency.

It should be noted that during the formation of multisectoral integrated organization's key competences should also take into account the factors of the institutional order. From the extent to which the development of multisectoral organization meets the requirements of the existing formal and informal social and economic institutions, such as, in particular, the institute of corporate governance, public-private partnership institute, elites institute, requirements for quality and quantity of generated and realized multisectoral organization competences depend directly.

In addition, using for the analysis of the characteristics and problems of interaction structures within the multisectoral company of economic and mathematical instruments of neoinstitutional economy, in particular the theory of 
games, is perspective direction of multisectoral integrated structures competencies research. On the basis of such instruments it is possible to analyze the efficiency of resource allocation between the multisectoral company structures and to analyze possible conflicts between different company departments by questions both a strategic development either operational cooperation, etc. This kind of neoinstitutional analysis could be complement the results of application of proposed multisectoral integrated organization comparative efficiency index.

\section{References}

Abrams R. Entrepreneurship: A Real-World Approach. (2012). Redwood City: Planning Shop.

Bulatov A.N., Mukhametshina G.R., Gazizullina A.R., Toropova N.V. (2014). The role of the project "Enterprise factory" in the competitiveness recovery of the regional economy of the Republic of Tatarstan. Mediterranean Journal of Social Sciences, 5 (12), 141-144.

Brown L. (2000). Integration models: templates for business transformation. NY: Sams.

Crump D. (2010). The holding company. NY: Quid Pro Books.

Drucker P.F. (2006). Innovation and entrepreneurship. NY: Harper Business.

Pescatore G. (1974). Cooperative organization in the context of integration. - Washington: CIRCOM.

Porter M.E. (2008). The five competitive forces that strategy. Harvard Business Review, 86 (1), 79 - 93.

Safiullin M.R., Safiullin A.R., Ermolaeva P.O. \& Noskova E.P. (2013). Interdisciplinary approach to the analysis of the competitiveness types of the economic activities based on the example of the oil and gas industry (Republic of Tatarstan case). Middle East Journal of Scientific Research, 18 (1), 42 - 49.

Safiullin M.R., Elshin L.A., Prygunova M.I. \& Galyavov A.A. (2013). Complex analysis of prospects of the Volga Federal District regions development: Methodology and practice. World Applied Sciences Journal, 27 (4), 508 - 511.

Ulesov D.V., Murtazina G.I. \& Safiullin L.N. (2013). Special aspects of development of business in the knowledge-based economy. World Applied Sciences Journal, 27 (13), 189 - 192. 